\title{
A PANDEMIA DO CORONAVÍRUS SOB A ÓTICA DA ANÁLISE ECONÔMICA DO DIREITO: (IN)EFICIÊNCIA DA INTERVENÇÃO ESTATAL?
}

\section{THE PANDEMIC OF THE CORONAVIRUS UNDER THE VIEW OF ECONOMIC ANALYSIS OF LAW: (IN)EFFICIENCY OF STATE INTERVENTION?}

\author{
Sandro Mansur Gibran ${ }^{1}$ \\ Juliana Markendorf Noda ${ }^{2}$ \\ Louvaine Locks ${ }^{3}$
}

\section{RESUMO}

O contexto pandêmico da Covid-19, apesar de recente, deixa sinais claros de ser um marco histórico para humanidade, não só pelas preocupações na área da saúde, considerando a velocidade extraordinária de sua propagação, mas também pelos seus reflexos em outras áreas, sinalizando uma recessão econômica de proporções ainda desconhecidas. Devido a uma forte atuação estatal presenciada nos últimos dias no campo normativo-jurídico, o artigo pretende analisar, partindo do exame das medidas já adotadas, o papel do Estado no direcionamento de ações visando atenuar os riscos e as incertezas decorrentes dos impactos econômicos e sociais decorrentes da pandemia. E, diante da complexidade da função regulatória, se analisa a eficiência das tentativas tradicionais e a perspectiva sob o viés da Análise Econômica do Direito como método, a fim de analisar o entrelace entre Direito e Economia.

Palavras-chave: Coronavírus; Intervenção Estatal; Análise Econômica do Direito.

\begin{abstract}
Covid-19's pandemic context, although recent, leaves clear signs of being a historic landmark for humanity, not only because of concerns in the health area, considering the extraordinary speed of its spread, but also for its reflexes in other areas, signaling an economic recession of unknown proportions. Due to a strong state action witnessed in the last days in the normativelegal field, the article intends to analyze, starting from the examination of the measures already adopted, the role of the State in directing actions aiming to mitigate the risks and uncertainties resulting from the impacts economic and social consequences of the pandemic. And, given the complexity of the regulatory function, the efficiency of traditional attempts and the perspective from the perspective of Economic Analysis of Law as a method are analyzed, in order to analyze the link between Law and Economics.
\end{abstract}

Keywords: Coronavirus; State intervention; Economic Analysis of Law.

\footnotetext{
${ }^{1}$ Advogado. Doutor em Direito Econômico e Socioambiental pela Pontifícia Universidade Católica do Paraná. Curitiba - Paraná - Brasil. sandro@ rochaadvogados.com.

${ }^{2}$ Advogada. Mestranda em Direito Econômico e Desenvolvimento pela Pontifícia Universidade Católica do

Paraná. Curitiba - Paraná - Brasil. juliana_mnoda@hotmail.com.

3 Advogada. Mestranda em Direito Econômico e Desenvolvimento pela Pontifícia Universidade Católica do Paraná. Curitiba - Paraná - Brasil. louvaine1@yahoo.com.br.
} 


\section{Notas introdutórias: o contexto pandêmico}

A humanidade vive um momento histórico em decorrência do coronavírus (Covid-19). Embora o cenário seja muito recente, a doença se alastra em uma velocidade inestimável pelo mundo inteiro, levando a Organização Mundial de Saúde (OMS) a classificá-lo como pandemia. Segundo dados divulgados pela Universidade Johns Hopkins (Estados Unidos), o vírus já infectou mais de um milhão de pessoas $^{4}$ (informação atualizada até o dia 02.04.2020), e os números tendem a subir.

Por outro lado, se estima que a recuperação ao impacto causado pela nova doença não andará na mesma velocidade, em especial sob o ponto de vista econômico. Serão necessários alguns longos anos para a recuperação mundial, conforme avaliou a Organização para a Cooperação e Desenvolvimento Econômico (OCDE). Em entrevista à BBC, Angel Gurría, secretário-geral, afirmou que "o choque econômico já é maior do que a crise financeira de 2008 ou a de 2001, após os ataques de 11 de setembro daquele ano"

Mesmo sem saber estimar o tamanho do desemprego e das falências empresariais, compreende não existir possibilidade de recuperação rápida, pois prevê que "quase todas as grandes economias do mundo entrarão, nos próximos meses, em recessão, ou seja, sofrerão declínio econômico por ao menos dois trimestres consecutivos" ${ }^{6}$. O cenário representa assim a maior incerteza instalada nas últimas décadas, mesmo com os governos ao redor do mundo tomando "medidas sem precedentes para apoiar trabalhadores e empresários durante a pandemia" 7 .

Os líderes governamentais, em diversas partes do mundo, estão usando todas as armas que podem para tentar evitar um colapso geral da economia, propondo medidas de contenção de perdas e de estímulo inimagináveis até o momento. Na iniciativa privada, as empresas também atuam intensamente para amortecer os efeitos do surto, buscando a sustentabilidade de seus negócios, o apoio aos seus funcionários e das comunidades, mesmo em meio a uma abrupta queda em seus negócios e rendimentos. 02.04.2020.

${ }_{6}^{5}$ Informação disponível em <https://www.bbc.com/portuguese/internacional-52002332> Acesso em 26.04.2020.

${ }^{6}$ Idem.

${ }^{7}$ Idem.
} 
A situação escapa ao controle do mercado. Se registraram quedas expressivas de dois dígitos nas principais bolsas de valores (o índice brasileiro Ibovespa já caiu $40 \%$ desde o começo de 2020), de modo que os governos precisaram adotar rapidamente uma série de medidas para conter a crise e a doença, desde pacotes de estímulo econômico até toques de recolher, fechamento de fronteiras e de setores não essenciais.

As medidas sustentam-se na busca da mitigação do contágio e na esperança do surto epidêmico se encerrar com mais brevidade, admitindo-se que se não tomadas estas e outras medidas de isolamento e restrição social, a economia tenderia a continuar seguindo em ritmo lento, mas ao doloroso custo do avanço da Covid-19 e da perda de vidas.

No Brasil, a chamada transmissão comunitária foi reconhecida pelo Ministério da Saúde em poucas semanas após as primeiras suspeitas. $\mathrm{O}$ aumento dos casos fez com que governadores e prefeitos estabelecessem medidas de contenção da propagação da doença de forma desordenada. Foi preciso a regulamentação da situação pelo Governo Federal, por meio de medida provisória e decreto do presidente Jair Bolsonaro, de modo a determinar, por exemplo, quais serviços essenciais não devem ser interrompidos por força da pandemia.

A Lei $n^{\circ}$ 13.979/2020 trouxe as medidas para enfrentamento da emergência de saúde pública de importância internacional decorrente do coronavírus e o Decreto $n^{\circ}$ 10.282/2020 tratou de regulamentá-la, de modo a definir os serviços públicos e as atividades essenciais que deveriam continuar funcionando. Normas embasadas no Decreto Legislativo $n^{\circ}$ 6/2020 que reconhece, para os fins do art. 65 da Lei Complementar $\mathrm{n}^{\circ}$ 101, de 4 de maio de 2000, a ocorrência do estado de calamidade pública.

A Conferência das Nações Unidas sobre Comércio e Desenvolvimento (UNCTAD), ocorrida no mês de março previu que a pandemia poderia custar à economia global até US\$ 2 trilhões neste ano (cerca de $\mathrm{R} \$ 10$ trilhões de reais). E a estimativa é de que o impacto em países fornecedores e vendedores de matérias-primas, como é o caso Brasil, será ainda mais agressivo, um dos motivos que ensejou a projeção oficial do governo brasileiro no percentual de crescimento em torno de $0,02 \%$ do PIB. O recuo na economia pode se dar em $4,4 \%$, em estimativas gentis.

O momento é de volatilidade tanto pelo vírus quanto pelo caos econômico, o que obrigou governos do mundo todo abandonarem suas cartilhas de austeridade fiscal e baixa intervenção do Estado na economia para injetar bilhões em auxílio para empresas e cidadãos. 
E até mesmo na ótica mais liberal de mercado, não há dúvidas de que é nesse contexto incerto e nebuloso que os governos precisam descobrir seu papel na mitigação dos efeitos perversos da pandemia sobre a sociedade e, especialmente, mitigar os possíveis danos.

\section{A intervenção estatal na Ordem Econômica}

O diálogo ou a interação entre a ordem jurídica e a ordem econômica é uma realidade há muito tempo admitida e especialmente estudada no direito econômico ${ }^{8}$. A preocupação sobre a intensidade e a forma de intervenção estatal na ordem econômica sempre teve importante destaque nos estudos dessa área do Direto. E não há como negar que o cenário de crise desencadeado pela pandemia do novo coronavírus reacende ainda mais o debate.

O texto constitucional brasileiro dedicou um título específico para tratar da ordem econômica e financeira ${ }^{9}$, impondo limites claros e objetivos para a iniciativa privada quanto ao livre exercício e a exploração das atividades econômicas e reservando ao Estado a possibilidade de intervenção no mercado para controle do poder econômico ${ }^{10}$.

A Constituição Federal, ao tratar dos princípios gerais da atividade econômica, aponta ser a livre iniciativa elemento fundante da ordem econômica, assegurando o livre exercício de qualquer atividade econômica, tal como previsto em seu art. 170. Em termos práticos, resguardou-se à iniciativa privada, o livre exercício e a exploração das atividades econômicas, concebendo assim o chamado livre mercado. De toda forma, não é segredo que referido conceito não é absoluto e deverá sempre ser enfrentado à luz dos demais fundamentos e garantias constitucionais.

O próprio art. 170 impõe limites ao exercício da livre iniciativa, estabelecendo a necessária observância a diversos princípios, como da soberania nacional, da função social da propriedade, da defesa ao meio ambiente e aos direitos do consumidor, da redução das desigualdades sociais, em consonância aos fundamentos e objetivos fundamentais da República, dentro dos quais se destacam a dignidade da pessoa humana, a construção de uma

\footnotetext{
${ }^{8}$ Como Manuel Afonso Vaz elucida “o funcionamento harmonioso de um determinado sistema económico requer um certo mínimo de regras de direito que assegurem a apropriação e o uso de factores de produção, dos produtos e dos serviços. Assim, o direito enquadra, rege ou normaliza a economia" (VAZ, 1998, p. 15)

${ }^{9}$ Artigos 170 a 181 da Constituição Federal.

${ }^{10}$ Característicos de um livre mercado.
} 
sociedade livre, justa e igualitária, além do desenvolvimento social, esculpidos nos arts. $2^{\circ}$ e $3^{\circ}$ da Constituição Brasileira.

Logo, a livre exploração das atividades econômicas foi estabelecida com parcimônia pela Carta Maior, até mesmo como forma de fazer valer os fundamentos e objetivos republicanos por ela eleitos.

A respeito do papel do Estado no controle do poder econômico, Egon Bockmann Moreira destaca que apesar da lógica liberal da livre concorrência apregoada pelos mercados, "é nítido que muitas vezes a atividade econômica pode se configurar ineficiente ou iníqua", constituindo as intituladas falhas de mercado. Os monopólios econômicos e tantas outras formas de abusos econômicos são verificadas corriqueiramente, notadamente em países subdesenvolvidos como o Brasil. Eros Roberto Grau ousou ser realista: "o poder econômico é a regra e não a exceção" (GRAU, 2005, p. 207).

Emergiria então, a intervenção do poder público na economia como necessária para conduzir e solver as ditas falhas de mercado. Apesar disto, o papel intervencionista do Estado não passa ileso de críticas. Afinal, o uso demasiado das ferramentas à disposição da máquina estatal também pode gerar desestímulo ao investimento e atuação no mercado brasileiro.

No entanto, a intervenção do Estado no mundo econômico não se reduz a corrigir falhas pontuais. Muitas vezes, se presta a redimensionar toda uma lógica econômica capaz de permitir a prevalência das políticas públicas vocacionadas ao interesse público por ele perseguido. Novamente socorrendo-se a doutrina do Professor Egon:

Ocorre que a intervenção não pode se dar apenas nesse plano de fascinação pelo mercado. Isso porque, ao mesmo tempo em que o Estado deve atuar para corrigir falhas nas condutas dos agentes (objeto de ilícitos concorrenciais), ele deve fazê-lo com a finalidade de sanar falhas estruturais (em setores onde o mercado e a concorrência dificilmente se instalariam) e implementar políticas econômicas públicas, instalando ab ovo modificações no próprio mercado. Tais políticas não são ancilares ao modelo mercadológico, mas inclusive podem contrariar o paradigma vislumbrado pela teorização da concorrência perfeita.

A inserção estatal na economia, portanto, muitas vezes transcende a formação de uma estrutura jurídico-institucional que apenas garanta o livre exercício da atividade econômica por parte das pessoas privadas, pois também se dirige ao exercício de atividade produtiva ou fomentadora. $O$ que se dá em especial em países subdesenvolvidos e/ou semi-industrializados.

Essa ordem de intervenções promocionais do Estado pode acidentalmente gerar resultados secundários equivalentes ao modelo da concorrência perfeita. Mas tal pressuposto não é condição necessária e suficiente para autorizar a interferência estatal. Não é necessário porque o fundamento de tais ações diz respeito às políticas públicas estabelecidas pelo Estado em função do interesse público por ele tutelado. Não é suficiente porque há hipóteses em que o Estado pode não se ver obrigado a só construir um mercado concorrencial perfeito, mas a atuar na geração de outros benefícios sociais (trabalho, renda, saúde, serviços públicos etc.) (MOREIRA, 2016, p. 120-121). 
Assim, como parte do controle da ordem econômica, e, portanto, do próprio poder econômico, se reservou ao Estado a possibilidade de intervir no mercado em determinadas hipóteses, embora se espere sua realização de forma mínima ${ }^{11}$.

Sem adentrar nos desdobramentos dessa atuação no mundo fático, de acordo com o aparato constitucional brasileiro, é permitido ao Estado agir naquelas situações em que exercerá funções normativas e regulatórias, com vistas a promover a fiscalização, incentivo e planejamento da atividade econômica (art. 174). Ainda, de forma direta, na exploração de determinadas atividades, por intermédio da criação uma empresa estatal para essa finalidade (art. 173).

De forma didática, a doutrina costuma dividir a participação ou ingerência do Estado na economia em duas frentes. Para Egon Bockmann Moreira “... a intervenção na economia é tomada como um conceito abrangente, que acolhe as espécies 'regulação' e 'intervenção em sentido estrito'..." (MOREIRA, 2016, p. 182). Na intervenção em sentido estrito - técnica de gestão ou endorregulação ${ }^{12}$ - há o efetivo ingresso do Estado no setor econômico, como na criação de empresa estatal para concorrer com as demais, hipótese do artigo 173 da Constituição Federal. Por outro lado, a regulação - ou como alguns preferem chamar de técnica normativa ou heterorregulação - se daria no campo jurídico, com o estabelecimento de normas capazes de atingir a finalidade pretendida. Há o que se chama de uma atuação do Estado sobre o domínio econômico. O amparo legal decorreria sobretudo do art. 174 da Constituição Federal.

No Brasil, após alguns anos de políticas voltadas a reforçar o papel do Estado no cenário econômico, o atual governo definia seu discurso em uma política direcionada a conferir maior liberdade e autonomia ao mercado, marcado pela edição da chamada Medida Provisória da Liberdade Econômica - no 881/2019, convertida posteriormente na Lei no 13874/2019 ${ }^{13}$. Em

\footnotetext{
${ }^{11}$ A propósito, fale reprisar as palavras de Rodrigo Fernandes Lima Dalledone ao comentar sobre o Programa de Parcerias de Investimentos - PPI (Lei n 13.334/2016): "Com efeito, as metas macroeconômicas de ampliação das ofertas de emprego e de investimento e desenvolvimento social e econômico dever ser obtidas por um modelo que privilegia a iniciativa privada, a livre concorrência ("ampla e justa competição", a segurança jurídica , além da eficiência e transparência da atuação pública, reservando ao Estado a função de ente regulador, de quem se espera a 'mínima intervenção nos negócios e investimentos' (arts. 2º $3^{\circ}$ )" (DALLEDONE, 2017, p. 198).

12 “... As técnicas (i) podem ser divididas em duas categorias básicas: (a) gestão; e (b) normativa. A gestão envolve o ingresso do regulador no mundo do ser de determinado setor econômico por meio da constituição de uma empresa para concorrer com as demais. Nesse caso, a regulação dar-se-ia dentro da Economia. Daí porque também é denominada de endorregulação. A regulação normativa, por sua vez, envolve a edição (ex ante) de normas (gerais e abstratas e/ou concretas). Tais normas pretenderão disciplinar a conduta dos agentes econômicos por meio da fixação de vantagens e punições..." (DEFANTI, 2017, p. 156).

${ }^{13}$ Altera diversas leis e "Institui a Declaração de Direitos de Liberdade Econômica; estabelece garantias de livre mercado".
} 
seu artigo inaugural, a referida Lei busca enfatizar o propósito do que chama de proteção à livre iniciativa e exploração, anunciando que:

Fica instituída a Declaração de Direitos de Liberdade Econômica, que estabelece normas de proteção à livre iniciativa e ao livre exercício de atividade econômica e disposições sobre a atuação do Estado como agente normativo e regulador, nos termos do inciso IV do caput do art. $1^{\circ}$, do parágrafo único do art. 170 e do caput do art. 174 da Constituição Federal.

Mas, como não poderia ser diferente, o referido dispositivo legal deixa clara sua aplicação em observância aos preceitos constitucionais da ordem econômica e financeira, incluindo naturalmente o papel do Estado na regulação e no direcionamento da economia.

O ponto é que a pandemia, independente da escolha política mais ou menos liberal, direcionou o próprio governo a uma nova realidade. A sociedade, de uma forma geral, assim como os mercados nacionais e globais, vive um momento historicamente impressionante. A tendência do abrandamento da intervenção do Estado no cenário econômico precisou tomar novo curso, forçado não por uma escolha meramente política, mas pela necessidade de respostas rápidas ao mercado e reforço da liquidez da economia como um todo.

Assim, o mecanismo normativo-jurídico é mais do que nunca usado como ferramenta pelo Estado para ações que tentam mitigar a crise desencadeada pela citada pandemia, tanto na área da saúde como na esfera econômica. Se vive uma verdadeira enxurrada de edição diária de normas jurídicas, em todas as esferas da Administração Pública, levando a uma percepção de uma intensa intervenção estatal na ordem econômica, como se pontuará a seguir.

\section{As principais medidas tomadas pelo Governo: o enfrentamento do Covid-19}

O momento atual tende a colocar o Estado como agente protagonista no direcionamento de medidas destinadas a assegurar a minimização de riscos e incertezas decorrentes dos impactos econômicos e consequentemente sociais decorrentes da pandemia do coronavírus.

Após o Congresso Nacional acolher a solicitação da Presidência da República e decretar a ocorrência do estado de calamidade pública por meio do Decreto Legislativo $\mathrm{n}^{\circ}$ 06/2020 de 20 de março de 2020, dispensando o atingimento dos resultados físcais 
estabelecidos anteriormente, observa-se o direcionamento de volumosos recursos para ações voltadas ao enfrentamento da crise para além das questões e preocupações na área da saúde.

Embora com as devidas reservas de serem transitórios e temporários, os instrumentos que estão sendo utilizados pelo governo para incentivar a economia são os mais variados possíveis, como o aumento das políticas assistencialistas e criação de novas, a flexibilização e adaptação de regras aplicáveis às relações privadas, trabalhistas e tributárias, o auxílio financeiro aos trabalhadores autônomos, a prorrogação de prazos para recolhimento de tributos, a prorrogação de prazo para recolhimento de FGTS por empregadores, pausas em pagamentos de financiamentos e empréstimos, o uso de bancos e recursos públicos para apoiar empresas e reduzir juros bancários, linhas de crédito especiais, dentre tantas outras medidas divulgadas na esfera federal, estadual e municipal.

Foram reduzidos os juros e taxas de referência, para manter a funcionalidade do mercado e auxiliar a sociedade, mesmo com o aumento do dólar tendo que ser controlado pelo Banco Central, o qual promoveu também a redução da alíquota de recolhimento compulsório sobre depósitos a prazo. O Banco Nacional de Desenvolvimento Econômico e Social suspendeu os pagamentos de parcelas de empréstimos vigentes pelo prazo de seis meses, além de se prontificar a oferecer mais 35 bilhões de reais em novos financiamentos a pequenas e médias empresas.

No âmbito federal, mais de uma dezena de medidas provisórias foram editadas pelo Presidente da República nos últimos dias, grande parte com o propósito de gerar estímulos na economia do país e promover a proteção social dos mais vulneráveis, de forma direta e indireta, incluindo até mesmo o aporte direto de recursos à iniciativa privada. As medidas vão desde a redução de alíquotas das contribuições aos serviços sociais autônomos ( $n^{\circ}$ 932/2020), suspensão do ajuste anual de preços de medicamentos para o ano de 2020 (nº 933/2020), até a liberação de recursos direcionados à iniciativa privada.

Somente por meio da Medida Provisória no 935/2020, foi aberto um crédito extraordinário de mais de 51 bilhões de reais em favor do Ministério da Economia, especialmente para fazer frente ao Programa Emergencial de Manutenção do Emprego e da Renda e pagamento do benefício previsto na Medida Provisória n 936/2020, além de liberação de crédito extraordinário de 98 bilhões ao Ministério da Cidadania para auxílio de caráter emergencial para proteção de pessoas em situação de vulnerabilidade devido a pandemia (Medida Provisória n 937/2020). 
O enfrentamento da crise também erradia efeitos no âmbito das relações de cunho privado. Está em votação o Projeto de Lei nº 1.179 de 2020, com o objetivo criar um regime emergencial e transitório das relações jurídicas, flexibilizando regras legais e contratuais durante a crise, como a mitigação das regras aplicáveis as relações locatícias e ao devedor de pensão alimentícia.

A gama de medidas interventivas tomadas pelo Governo Brasileiro é imensa ${ }^{14}$ e estes são alguns poucos exemplos do movimento para enfrentamento dos intempéries da pandemia do Covid-19 no aspecto econômico e social, considerando que o esgotamento do tema exigiria um espaço muito maior que o aqui estudado, mas serve para elucidar que a situação emergencial exige respostas rápidas e técnicas, além da mobilidade característica das normas entrelaçadas do Direito e da Economia e de um papel muito mais ativo do Estado daquele visto em outras épocas.

Serve também para confirmar que o Estado, na qualidade agente normativo e regulador da atividade econômica, pode valer-se amplamente de diversas ferramentas para direcionamento das políticas excepcionais e de sustentação das medidas aos fins almejados, desafiando um olhar atento para que este arsenal estatal seja utilizado com equilíbrio e não como um verdadeiro "cheque em branco".

Ainda é cedo para se avaliar os efetivos impactos e a extensão da crise iniciada com a pandemia, assim como se as medidas trarão ou benefícios almejados para mitigação dos efeitos sociais e econômicos, mas objetiva-se, desde logo, trazer para reflexão alguns pontos relativos eficiência da intervenção dentro deste contexto.

\section{A eficiência da intervenção: sob a ótica da Análise Econômica do Direito}

Feitas as considerações sobre a intervenção estatal e as medidas tomadas a fim de evitar o alastramento da doença ocasionada pelo coronavírus, parte-se, portanto, da análise da eficácia da atitude interventiva do poder público na economia, sob a ótica da Análise Econômica do Direito.

\footnotetext{
${ }^{14}$ Todas as principais medidas podem ser consultadas no sítio eletrônico do Ministério da Economia, informação disponível em <https://www.gov.br/economia/pt-br/assuntos/noticias/2020/marco/confira-as-medidas-tomadaspelo-ministerio-da-economia-em-funcao-do-covid-19-coronavirus> Acesso em 02.04.2020.
} 
A regulação perpetrada pelo Governo Federal, portanto, reside naquela denominada heterorregulação, aquela que se dá no campo jurídico, com o estabelecimento de normas capazes de atingir a finalidade pretendida - que aqui claramente é mitigar os danos ocasionados pela doença. Dessa atuação sobre o domínio econômico, afere-se que suas tarefas centrais são “justificar quem receberá os benefícios ou quem arcará com os ônus da regulação, qual forma a regulação tomará e quais os efeitos desta sobre a alocação de recursos" (STIGLER, 2004, p. 23).

Importante ressaltar que o sucesso dessa vertente reside na expansão da sua iluminação a outras áreas, inclusive aquelas que não tratam do comportamento do mercado, pois a teoria econômica toma forma quanto ao comportamento humano, compreendido como resposta de seres racionais individualistas ao meio ambiente, devendo possuir aplicação também no processo político (POSNER, 2004, p . 74).

Enquanto o ente interventor se posiciona dentro dos preceitos constitucionais, suas incumbências são prestadas com louvor, mas a partir do momento que ultrapassa os limites postos, é que temos o problema na regulação ou a solução de uma situação maior. E, diante dessa complexidade regulatória é que se analisa a eficiência das suas tentativas tradicionais, buscando socorro na Análise Econômica do Direito como método, a fim de analisar o entrelace entre Direito e Economia que se propõe no presente trabalho, considerando que, como toda modalidade de análise, pode ser criticada, refinada e até repensada integralmente, até em suas mais profundas hipóteses e conclusões (ACCIARRI, 2014, p. 246).

Thomas Ulen (2017, p. 18) bem aponta que a relação do Direito com a Economia constitui um método frutífero, porque a Economia trouxe o método científico ${ }^{15}$ para o estudo do Direito, já que teoriza a decisão dos indivíduos com relação a incentivos e demonstra técnicas empíricas para avaliá-la, enquanto que o Direito é um método de governança, que orienta o comportamento daqueles submetidos à determinada jurisdição, por meio de regras e normas ${ }^{16}$. Assim, compreende-se a interseção entre Direito e Economia como um "conjunto de ferramentas analíticas que podem complementar as ferramentas já tradicionalmente utilizadas pelo Direito" (ULEN, 2017, p. 35).

O caso caótico que se presencia atualmente foge de qualquer situação já vivida, especialmente em termos econômicos. Para além de todas as questões relacionadas à saúde e

\footnotetext{
${ }^{15}$ Esse método significa o estudo pela articulação de hipóteses coerentes sobre fenômenos reais atrelada à análise sistemática de dados concernentes à probabilidade estatística do acerto das hipóteses (Cf. ULEN, 2002, p. 875). ${ }^{16} \mathrm{Ou}$ seja, consolida-se a análise do processo de tomada de decisões, de modo a maximizar a utilidade ou bem-estar, observando as imperfeições do mercado (ex. monopólios), custos externos e graves assimetrias de informação (ULEN, 2017, p. 20).
} 
as mortes advindas dessa pandemia, a onda de crise econômica já tomou posição e se alastra cada vez mais. Na busca da contenção dessa onda, o Governo tomou diversas medidas, com ênfase nas principais citadas no tópico anterior, intervindo diretamente na Ordem Econômica.

Aqui cabe expor o ponto do autor Douglass C. North, que desenvolveu valioso artigo intitulado "Economic Performance Through Time", no qual aborda a questão da natureza das instituições e a forma como elas afetam o desempenho econômico com o passar do tempo, bem como a promoção da mudança institucional por meio da ciência cognitiva para a aprendizagem humana, de modo a fornecer uma abordagem cognitiva da história econômica, para melhorar a compreensão do passado e sugerir implicações para as políticas atuais de desenvolvimento.

Isto pois, entendeu que o Estado, certas vezes, acaba por prescrever políticas sem necessariamente analisar os aspectos econômicos envolvidos na situação, o que enseja o seguinte questionamento: "how can one prescribe policies when one doesn't under stand how economies develop?" (NORTH, 1994, p. 359). Para o autor, se o globo fosse incutido da racionalidade instrumental que experimentasse mercados eficientes ${ }^{17}$ econômica e politicamente ${ }^{18}$, de modo a não serem valoradas ideologias, a desnecessidade da presença das instituições seria inevitável.

Entretanto, seu estudo adentra na lógica do desempenho econômico em uma situação de normalidade, obviamente. Nesse ponto, contrariando a lógica do autor, o Estado Brasileiro tem promovido forte intervenção econômica por meio de suas instituições, em virtude do estado de emergência implantado pelo Covid-19. Para tanto, seria essa postura eficiente?

Importante assinalar que o conceito de eficiência aqui tratado parte do pressuposto daquele defendido por Pareto (1984), situação na qual não se pode melhorar um dos sujeitos envolvidos sem prejudicar o outro (ACCIARRI, 2014, p. 27). Como essa ótica resta demasiado exigente, visto que caso haja dano a um indivíduo não se considera eficiente, é que se utiliza os critérios denominados potenciais de Pareto "para descrever aquelas situações nas quais há indivíduos inicialmente prejudicados pela mudança, mas o benefício daqueles que foram favorecidos é tal que seria suficiente para compensar integralmente os prejuízos dos desfavorecidos"(ACCIARRI, 2014, p. 27).

\footnotetext{
${ }^{17}$ Mercados eficientes são aqueles criados "in the real world when competition is strong enough via arbitrage and efficient information feedback to approximate the Coase zero-transaction-cost conditions and the parties can realize the gains from trade inherent in the neoclassical argument" (NORTH, 1994, p. 360).

${ }^{18}$ Mercados econômicos eficientes são raros de se encontrar e, mercados políticos são impossíveis. Isto pois, os custos de transação como aqueles especificam o que é trocado e fazem cumprir os acordos, no político significa a troca de votos entre eleitores e legisladores, de modo que o eleitor tem pouco incentivo a informação (Ibid., p. $361)$.
} 
Assim, a eficiência como objetivo valioso (ACCIARRI, 2014, p. 46) se manifesta em situações nas quais se percebe razoável exigir de alguém um esforço privado, quando esse ônus determine um benefício que estimamos superior para outros membros da sociedade (ACCIARRI, 2014, p. 46).

É importante destacar esse conceito, para se recorrer à teoria econômica de Pigou, que incorporou as externalidades na Economia, considerando que o indivíduo afetado por determinada situação é o único detentor da informação de quanto foi afetado, enquanto que no Direito há a busca por critérios objetivos para realizar essa ponderação (ACCIARRI, 2014, p. 28), juntamente com a influência que exerce na conduta humana, o que pode ser verificado nas consequências empíricas das normas jurídicas efetivadas (ACCIARRI, 2014, p. 46).

Há quem acredite, por exemplo, que o combate exitoso da doença na China é fruto do modelo econômico, em virtude da forte presença estatal. Isto pois, focado nas denominadas “capacidades estatais", o país asiático supostamente conseguiria planejar intervenções rápidas sobre o território e a existência das duas instituições monopolizadoras do poder (o Partido Comunista e o Estado socialista) seriam capazes de operar grandes ondas de inovações institucionais necessárias à continuidade do processo de desenvolvimento, por meio de uma planificação econômica com base em um amplo aparato produtivo e financeiro. Porém, para além de todas as críticas ao modelo econômico chinês, não é novidade ${ }^{19}$ que nem ao menos pode-se afirmar se os dados divulgados estão em consonância com a realidade.

O que as medidas interventivas governamentais brasileiras assinalam na prática, apesar da discussão ainda muito recente, é que, primeiramente, como diz o ditado popular: o excesso de informação gera a desinformação. Isto pois, é impossível prever todos os efeitos que as medidas irão desencadear, inclusive em virtude da edição dessas novas ferramentas, praticamente todos os dias. Ponto relevante na análise do presente trabalho que, de maneira ousada, buscou fazer um estudo sobre o tema no "olho do furacão".

Posteriormente, tem-se que a atuação governamental tem tentado mitigar os danos oriundos da situação caótica, mas que não tem estrutura para agir sozinha, pelo simples fato de que a economia depende dos seus agentes, principalmente das empresas. Não poderia ser diferente, pois no Brasil, "os 8,9 milhões de micro e pequenas empresas respondem por um quarto do PIB e mais de $50 \%$ dos empregos com carteira assinada" ${ }^{20}$.

\footnotetext{
${ }^{19}$ Informação disponível em <https://www1.folha.uol.com.br/equilibrioesaude/2020/02/assim-como-a-chinabrasil-ja-censurou-dados-sobre-surto-durante-ditadura.shtml> Acesso em 02.04.2020.

${ }^{20}$ Informação disponível em <https://exame.abril.com.br/revista-exame/quem-vai-salvar-a-economia/> Acesso em 02.04.2020.
} 
É por isso que se pode extrair que, diante da intervenção estatal por meio da regulamentação, as próprias estruturas de ordem social buscam regular o comportamento dos indivíduos e definir os incentivos das economias, os custos de transação ${ }^{21}$ e a consequente transformação com os custos de produção. Nesta seara, observa-se a forte atuação privada no combate da epidemia.

Assim, podem ser citadas ações de empresas como o iFood, grupo que ocupa lugar central na discussão "porque dá ocupação a 300.000 entregadores autônomos, parte da massa de 38 milhões de informais do país, e tem mais de 10 milhões de clientes que podem usar o serviço para manter a roda da economia girando" 22 . A empresa criou um fundo de 1 milhão de reais para continuar pagando os entregadores que forem diagnosticados ou apresentarem sintomas do novo coronavírus, bem como realizou doação de 50 milhões de reais para socorrer pequenos estabelecimentos parceiros.

Ou a ação do Facebook, que anunciou a concessão de 100 milhões de dólares em doações em dinheiro e créditos de anúncios para até 30.000 pequenas empresas em mais de 30 países.

Já o Uber também manteve os pagamentos aos colaboradores que precisarem entrar em quarentena ou apresentarem sintomas e diversas instituições de ensino no país e no mundo inteiro disponibilizaram cursos e bibliotecas gratuitamente por meio das suas plataformas. $\mathrm{O}$ Burger King Brasil vai doar cerca de 1 milhão de reais de sua receita ao Sistema Único de Saúde (SUS), a Ambev vai produzir e doar 500.000 garrafas de álcool em gel a hospitais municipais e a Natura e a Avon doarão 2,8 milhões de sabonetes a comunidades carentes no entorno de suas fábricas. Nesse sentido:

\footnotetext{
Segundo Carlo Pereira, diretor executivo da Rede Brasil do Pacto Global da Organização das Nações Unidas, o papel das empresas na sociedade está mudando. "Há um entendimento de que as corporações se tornaram mais relevantes, tanto que, hoje, as pessoas confiam mais em seu empregador do que no governo", diz ele. É o que mostra uma pesquisa realizada pela Edelmann, empresa americana de relações públicas, com a participação de 2 milhões de pessoas de 28 países. A confiança nas companhias, de forma geral, é maior do que nos governos, $58 \%$ ante $49 \%$. Quando se trata da empresa em que a pessoa trabalha, o índice sobe para 76\%. "Essa pandemia
}

\footnotetext{
${ }^{21}$ Conceito este preconizado por Coase como o custo de saber com quem negociar e quais informações utilizar para conduzir a transação, sua elaboração e posterior fiscalização (COASE, 1937, p. 336). Posteriormente, Arrow, considerou os custos de transação como aqueles necessários para se recorrer ao sistema econômico (ARROW, 1969) e, ainda, Williamson os desenvolveu como aqueles incorridos para planejar e monitorar as estruturas de governança (WILLIAMSON, 1985).

${ }_{22}$ Informação disponível em <https://exame.abril.com.br/revista-exame/quem-vai-salvar-a-economia/> Acesso em 02.04.2020.
} 
mudará a maneira como as companhias atuam", diz Pereira. "A simbiose entre empresas e sociedade ficará mais evidente."23

Considerando que não há empresa sem sociedade, são elas que, junto ao governo, compõe estruturas que pretendem promover as mudanças econômico-sociais, que passa por três pontos principais (NORTH, 1994): (a) a compreensão das regras formais, informais e características de execução que moldam o desempenho econômico, (b) as políticas e suas respectivas regras como influência no desempenho econômico e (c) a eficiência adaptativa e não alocativa, essencial para o crescimento a longo prazo.

Para obter o sucesso econômico, portanto, o sistema deve desenvolver "flexible institutional structures that can survive the shocks and changes that are a part of successful evolution (...) We do not know how to create adaptive efficiency in the short run" (NORTH, 1994, p. 367), motive pelo qual a dificuldade atual em lidar com os desafios advindos da crise ocasionada pelo Covid-19. Essa flexibilidade é necessária pois racionaliza o uso do capital, alocando-o nas melhores condições de mercado (DUPAS, 2011, p. 33), isto pois "a economia nada mais é que um sistema complexo em que os agentes, dotados de racionalidade e escolha, desenvolvem e satisfazem as suas infinitas necessidades" (PAGANI, 2019, p. 9).

É nessa questão que surge a análise do papel indutor e regulador do Estado e "se cabe a ele ou à sociedade por meio dele definir padrões éticos que condicionem a aplicação das técnicas" (DUPAS, 2011, p. 108). Isto pois, é instituto detentor do poder, que legitima a ciência e o direito por sua eficiência (DUPAS, 2022, p. 117), podendo incorrer em situações de prejuízo social e econômico.

A análise concreta da eficiência da intervenção estatal perpetrada - em muito - com objetivos econômicos, por meio da regulamentação jurídica, só poderá ser aprofundada quando começarem a surgir os problemas da depressão da epidemia e sua consequente quarentena. $\mathrm{O}$ que se pode aferir atualmente é que o colapso econômico poderá advir não da ineficiência da atuação estatal, mas sim da imprevisibilidade econômica frente ao pânico social e ao fator de expectativa em relação aos indivíduos.

Como diversas situações no país já assinalam, houve confisco de produtos e propriedades, o que gera insegurança jurídica para a sociedade em um contexto geral. Isto pois, o tecido social pode romper pela noção de incerteza, tendo em vista que as pessoas não possuem expectativa do mercado e não sabem o que pode ocorrer no dia seguinte, de modo que se instaure o pânico, o caos e a consequente recessão.

${ }^{23}$ Idem. 


\section{Conclusões}

O presente trabalho serviu para levantar diversos questionamentos acerca da intervenção estatal e a sua (in)eficiência no atual cenário de epidemia implantado pelo coronavírus. Poucas são as conclusões que podem ser extraídas, tendo em vista a absurda atualidade do tema, especialmente em termos de regulamentação.

Entretanto, é necessária a reflexão, já que em tempos como esse é comum a sociedade questionar o modelo de governo e o modelo econômico. Para tanto, tem-se clareza que, a intervenção, em um primeiro momento, parece ser positiva, especialmente se tomando em consideração as notícias extraídas diariamente, como, por exemplo, a reação positiva na última semana de março dos mercados globais quanto à expectativa da aprovação de pacote de estímulos econômicos de cerca de US\$ 2 trilhões Senado dos Estados Unidos.

Entretanto, é cristalino que a intervenção deve ser pontual devido ao estado de calamidade pública e não pode se transformar em um cheque em branco para o Estado tomar as medidas que bem entender. Assim, a regulamentação jurídica deve ser limitada para que possa, também, continuar recebendo o auxílio da esfera privada na contenção da crise.

Isto para não impor à sociedade o colapso econômico, que pode advir não apenas da ineficiência da atuação estatal, como também da imprevisibilidade econômica frente ao pânico social e ao fator de expectativa financeira. Deve-se atentar para uma regulamentação que gere o menor grau de insegurança jurídica possível e sirva de norte para as expectativas individuais, não de âncora como pretendem os modelos antiliberais, de modo a conter o medo e o caos que podem gerar efeitos muito mais devastadores e uma recessão intensa.

\section{Referências Bibliográficas}

ACCIARRI, Hugo A. Elementos da Análise Econômica do Direito dos Danos. Coord. Marcia Carla Pereira Ribeiro. São Paulo: Editora Revista dos Tribunais, 2014.

ARROW, K. J. The Organization of economic activity: issues pertinent to the choice of market versus nonmarket allocation. In: The Analysis and evaluation of public expenditure. Cambridge: Harvard University Press, 1969.

COASE, R. H. The Nature of the Firm. Economica, 1937. 
DALLEDONE, Rodrigo Fernandes Lima. O Programa de Parceira de Investimentos (PPI) e o papel do Estado na economia. Revista de Direito Público da Economia: RDPE, ano 15, $n^{\circ} 57$. Belo Horizonte: Fórum, janeiro/março - 2017.

DEFANTI, Francisco. Reserva de Regulação da Administração Pública. Revista de Direito Público da Economia: RDPE, ano 15, n 57. Belo Horizonte: Fórum, janeiro/março - 2017.

DUPAS, Gilberto. Ética e poder na sociedade da informação: de como a autonomia das novas tecnologias obriga a rever o mito do progresso. 3. Ed. São Paulo: Editora UNESP, 2011.

GRAU, Eros Roberto. A ordem econômica na Constituição de 1988. 17. ed. São Paulo: Malheiros, 2005.

MOREIRA, Egon Bockmann. O direito administrativo contemporâneo e suas relações com a economia. Curitiba: Editora Virtual Gratuita - EVG, 2016.

NELSON, R.R. Bringing institutions into evolutionary growth theory. Journal of Evolutionary Economics, 2002, p. 12:17-28.

NORTH, Douglass C. Economic Performance Through Time. In: The American Economic Review, Vol. 84, No. 3 (Jun., 1994), pp. 359-368. Disponível em <http://www.jstor.org/stable/2118057> Acesso em 12 de outubro de 2017.

OLIVEIRA, Marcella Gomes de; OPUSZKA, Paulo Ricardo. Direito e atividade econômica - uma análise interdisciplinar sobre a intervenção estatal. Revista Jurídica, [S.1.], v. 2, n. 35, p. 445-463, nov. 2014. ISSN 2316-753X. Disponível em: <http://revista.unicuritiba.edu.br/index.php/RevJur/article/view/968/666>. Acesso em: 23 abr. 2020. doi:http://dx.doi.org/10.21902/revistajur.2316-753X.v2i35.968.

PAGANI, Lucas Augusto Gaioski. Direitos fundamentais, a propriedade e a função social: a função social da propriedade como fundamento do desenvolvimento econômico, político e social. In: MISES: Interdisciplinary Journal of Philosophy Law and Economics. São Paulo, 2019; 7(1) Jan-Apr.

PARETO, Vilfredo. Manual de Economia Política. São Paulo: Abril Cultural, 1984.

POSNER, Richard. Teorias da Regulação Econômica. In: Regulação econômica e democracia: o debate norte-americano (Coord. Paulo Mattos). São Paulo: Ed. 34, 2004.

STIGLER, George J. A Teoria da Regulação Econômica. In: Regulação econômica e democracia: o debate norte-americano (Coord. Paulo Mattos). São Paulo: Ed. 34, 2004.

ULEN, Thomas S. Direito e Economia para Todos. In: Estudos sobre Negócios e Contratos: uma perspectiva internacional a partir da análise econômica do direito. Almedina, 2017.

ULEN, Thomas S. A Nobel Prize in Legal Science: Theory, Empirical Work, and the Scientific Method in the Study of Law. 2002. III, Ver. 875. 
VAZ, Manuel Afonso. Direito Económico. 4ª ed. Coimbra: Coimbra Ed., 1998.

WILLIAMSON. Oliver E. The Economic Institutions of Capitalism: firms, markets, relationsl contracting. London: Collier Macmillan Publishers, 1985. 